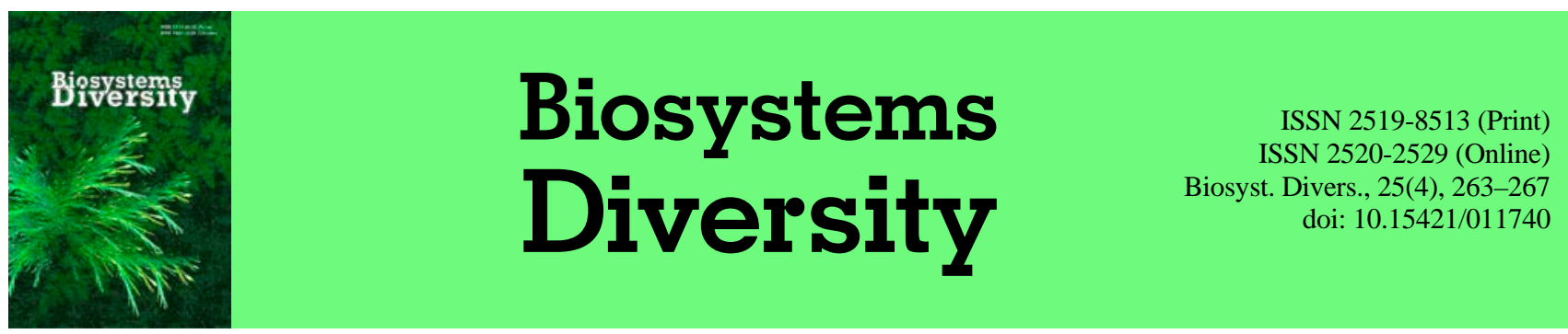

\title{
Ecologo-faunistic review of lamellicorn beetles (Coleoptera, Scarabaeoidea) of urbocenosis of Kharkov city (Ukraine)
}

\author{
O. V. Putchkov*, T. Y. Markina**, N. Komaromi** \\ *Schmalhausen Institute of Zoology of the NAS of Ukraine, Kyiv, Ukraine \\ **H. S. Scovoroda Kharkiv National Pedagogical University, Kharkiv, Ukraine
}

\section{Article info}

Received 19.09.2017

Received in revised form 07.11 .2017

Accepted 10.11.2017

Shmalhausen Institute of Zoology of the NAS of Ukraine, Bohdan Chmelnitsky st., 15, Kyiv, 01030, Ukraine.

Tel.: +38-044-235-10-70

E-mail:

putchkov@izan.kiev.ua

H. S. Scovoroda Kharkiv National Pedagogical

University, Alchevskych st. Kharkiv, 61002,Ukraine. Tel.:+38-057-268-14-34 E-mail:

tyu.markina@gmail.com nkomaromi@gmail.com
Putchkov, O. V., Markina, T. Y., \& Komaromi, N. (2017). Ecologo-faunistic review of lamellicorn beetles (Coleoptera, Scarabaeoidea) of urbocenosis of Kharkov city (Ukraine). Biosystems Diversity, 25(4), 263-267. doi:10.15421/011740

This article presents a general overview of the superfamily Scarabaeoidea in five parks of Kharkov city and some adjacent agrocenosises. The species composition includes 32 species from four families of Scarabaeoidea. The Scarabaeidae family dominated in biodiversity and abundance (26 species from 16 genera). Six species (Dorcus parallelopipedus, Platyderes caraboides, Anoplotrupes stercorosus, Aphodius melanostictus, Pleurophorus caesus and Onthophagus coenobita) were sporadically registered as common, but in separate urban cenosises the number of species did not exceed one or three. The species composition and abundance of lamellicorn beetles was higher in large parks with only slight recreational disturbance. Here from 13 to 20 species were registered. On lawns in the center and in other districts of the city Scarabaeoidea species met very rarely. In the agrocenosises on the outskirts of Kharkov city -16 species are noted, almost half of which were registered as common. The faunistic similarity of different urban cenosises was at low to medium levels (an average $0.20-0.47$ ). These indices were slightly higher $(0.38-0.67)$ for areas with lower recreational pressure. The indices of faunal similarity of separate parks and agrocenoses were lower $(0.18-0.56$, but on average - 0.33). At the level of common species, there was no faunistic similarity. The significance of such differences was due to both the low number of most Lamellicorn species and some of their ecological characteristics. The main differences were observed in the ratio of trophic groups and features of the spatial distribution of the dominant species. Smaller differences were observed on biotopic characteristic of most species. There were no differences in the hygropreference of the scarabeid species. In the parks herpetobiont saprophagous species dominated (mainly coprophagous and dendrophagous). In the agrocenoses, dendrochordobiontic phytophagous species predominated. The peculiarities of the ratio of different ecological groups of Scarabaeoidea in urban and agrocenosises are discussed.

Keywords: Scarab beetles; species composition; faunistic similarity; ecological groups; parks; city

\section{Эколого-фаунистический обзор пластинчатоусых жуков (Coleoptera, Scarabaeoidea) урбоценозов Харькова (Украина)}

\author{
О. В. Пучков*, Т. Ю. Маркина** , Н. А. Комароми** \\ *Институт зоологии имени И. И. Шмальгаузена НАН Украины, Киев, Украина \\ **Харьковский начиональный педагогический университет имени Г. С. Сковороды, Харьков, Украина
}

В результате исследований в пяти парках г. Харьков выявлено 32 вида из четырех семейств Scarabaeoidea. По видовому составу и численности доминировали представители семейства Scarabaeidae (26 видов из 16 родов). Обычными оказались шесть видов, причем в отдельных урбоценозах их число не превышало одного-трех видов. Видовой состав и численность скарабеоидных жуков оказались выше в крупных, рекреационно слабо нарушенных парках, где отмечено от 13 до 20 видов. На газонах как в центре города, так и в отдаленных микрорайонах, пластинчатоусые жуки встречались единично. В прилегающих к Харькову агроценозах отмечено 16 видов, из которых почти половина - обычны. Среднее фаунистическое сходство Scarabaeoidea в разных парках оказалось невелико (0,20 по Жаккару и 0,47 по Чекановскому - Серенсену). Эти показатели были чуть выше $(0,38-0,50$ / 0,61-0,67) для территорий с меньшей рекреационной нагрузкой. Фаунистические индексы отдельных парков и агроценозов составляли 0,18-0,31 / 0,31-0,56 (в среднем - 0,33 / 0,50). На уровне обычных видов, фаунистическое сходство отсутствует. Значимость таких различий обусловлена как низкой численностью большинства видов, так и некоторыми экологическими характеристиками видов. Основные различия наблюдались в соотношении трофических групп и особенностях пространственного распределения доминантных видов. Меньшие различия отмечены при сравнении видов по биотопической приуроченности и гигропреферендуму. По трофической специализации в парках доминировали герпетобионтные сапрофаги разной специализации (в основном копрофаги и дендрофаги), тогда как в агроценозах преобладали фитофаги - дендрохортобионты. Обсуждены особенности соотношения разных экологических групп Scarabaeoidea в урбо- и агроценозах.

Ключевые слова: скарабеоидные жуки; видовой состав; фаунистическое сходство; экологические группы; городские парки 


\section{Введение}

Для выяснения причин изменений экологического равновесия трансформированных ценозов, одними из которых являются урболандшафты, необходим эколого-фаунистический мониторинг с целью оценки и прогнозирования степени их устойчивости и закономерностей формирования (Markina and Zlotin, 2014). Наличие уникальных экологических ниш в условиях городов вместе с особыми климатическими особенностями приводит к появлению специфического населения животных, в том числе и энтомофауны. Одним из важных ее компонентов являются жесткокрылые насекомые (Coleoptera), среди которых значительную роль играют представители надсемейства Scarabaeoidea. Многие виды этой группы - сапрофаги, участвующие в трансформации органических остатков, или фитофаги, в том числе и вредители сельского и лесного хозяйств. Некоторые представители надсемейства, являющиеся гео- и герпетобионтными видами, могут служить индикаторами изменения почвенных условий.

Исследованиям этой группы жуков (филогении, систематики, их экологической структуры в разнообразных экосистемах) посвящены многочисленные работы (Browne and Scholtz, 1999; Galante and Cartagena,1999; Price, 2004; Verdú et al., 2004; Smith, 2006; Dortel et al., 2013; Buse et al., 2015; Buyvolova et al., 2016). Однако сведения о представителях надсемейства в условиях города крайне немногочисленны, даже на фаунистическом уровне. Относительно более-менее детальные исследования видового состава этих жуков (главным образом герпетобионтов) проведены в некоторых урбоценозах Белоруссии (города Минск, Гомель) (Molodova, 1991; Galinovskiy, 2006).

В трансформированных ценозах Украины, ряд сведений о структуре скарабеоидных жуков приведены, главным образом, для агроценозов (Putchkov, 1990; Sumarokov, 2009) и, в меньшей степени, для залежных участков (Putchkov and Gavrilyuk, 2010). Некоторые общие (но весьма поверхностные) данные для двух семейств (Scarabaeidae, Lucanidae) парков Харькова представлены в отдельных статьях (Dekhtyarova, 2002; Putchkov et al., 2016). Вместе с тем, именно углубленные исследования колеоптерофауны (как и других насекомых), позволяют не только получить интересные фаунистические данные, но и оценить особенности формирования и возможность сохранения представителей той или иной группы насекомых в условиях разных элементов урболандшафтов - парков, скверов, садов.

\section{Материал и методы исследований}

Изучение пластинчатоусых жуков проводили в период 20152017 гг. при исследованиях видового состава и экологической структуры жуков (главным образом - герпетобионтов) четырех парков Харькова (Лесопарк, Карповский сад, Победы, Зеленый гай), характеристика которых приведена ранее (Putchkov et al., 2016). Для сравнения учеты проводили и в некоторых агроценозах окраин Харькова (огороды, небольшие поля зерновых, сады). При исследованиях использовали главным образом почвенные ловушки Барбера (пластиковые стаканчики емкостью 0,2 л, заполненные $10 \%$ раствором уксусной кислоты). Выборку насекомых проводили с 10-15-дневными интервалами с начала мая до конца сентября. В каждом биотопе выставлено по 10-30 ловушек. Для оценки сходства видового состава насекомых отдельных участков использовали коэффициент видового сходства Жаккара и (для сравнения) - Чекановского - Серенсена. По уровню численности (учитывая незначительность общего числа отловленных особей около 400 экз.) выделено три группы: обычные (более 5\% от общего числа отловленных видов надсемейства), редкие (менее 5\%) и единичные (от одного до трех экземпляров). Дополнительно жуков регистрировали и собирали при маршрутных экскурсиях по городу путем обследования отдельных травянистых растений, кустарников и деревьев на всех указанных участках и прилегающих территориях, а также кошением энтомологическим сачком.
Классификация надсемейства приведена по каталогу жуков Палеарктики (Catalogue of Palearctic Coleoptera..., 2006). Характеристика экологической структуры (по имаго) дана на основании литературных сведений (Martynov, 1997; Vas'ko, 2010). Следует отметить, что полученные данные носят предварительный характер и будут углублены в ходе дальнейших исследований.

\section{Результаты}

Всего в урбоценозах Харькова зарегистрировано 32 вида пластинчатоусых жуков из 22 родов и 4 семейств - Scarabaeidae (27), Geotrupidae, Lucanidae (по 2) и Troxidae (1 вид) (табл. 1). По разнообразию видового состава доминировали представители родов Aphodius (10) и Onthophagus (5 видов). При этом число видов по разным паркам колебалось от 10 до 20, а на открытых газонных участках единично отмечен один вид (Pleurophorus caesus). Количественно пластинчатоусые жуки оказались редкой (только иногда субдоминантной) группой в большинстве парков, а их доля среди всего отряда Coleoptera составляла от 0,6 (Карповский сад) до 2,1 (Лесопарк) и 3,4\% (парк Победы). На крайне урбанизированных участках (газоны центра и жилых микрорайонов города) доля Scarabaeoidea не превышала $0,05 \%$. При сравнении с агроценозами необходимо отметить, что здесь общая количественная доля пластинчатоусых жуков почти не отличалась от городских парков и колебалась в пределах $0,8-2,5 \%$ всего отряда.

Только шесть видов пластинчатоусых жуков, отмеченных в парках (Dorcus parallelopipedus, Platyderes caraboides, Anoplotrupes stercorosus, Aphodius melanostictus, Pleurophorus caesus и Onthophagus coenobita), зарегистрированы как спорадично обычные (причем по отдельным участкам, их число составляло от одного до трех видов). Как редкие отмечено 15 видов, а остальные (более 10) встречались единично (табл. 1). Отмечены определенные различия в качественно-количественной характеристике скарабеидофаун разных парковых участков. Наибольшее число видов зафиксировано в типичных парковых ценозах, со слабо иссушенной почвой. На территории парков Карповский сад и Победы отмечено 19-20 видов, но из них только Onthophagus coenobita оказался спорадически обычен, а остальные - зарегистрированы как редкие или единичные. На территориях парков Зеленый гай и Харьковский лесопарк выявлено соответственно 10 и 13 видов жуков, из которых только в последнем относительно обычными были три вида (Dorcus parallelopipedus, Platyderes caraboides, Anoplotrupes stercorosus).

В то же время в агроценозах, прилегающих к Харькову, отмечено 16 видов пластинчатоусых жуков из 11 родов и трех семейств (табл. 1). Из них восемь видов являлись доминантами или субдоминантами. Это объясняется преобладанием здесь ряда вредителей сельского и лесного хозяйств, которые не часто встречаются в урбоценозах. В садах доминировали Melolontha melolontha и Amphimellon solstitiale, а на полевых культурах - Pentodon idiota, Chaetopteriphilus segetum, Anisoplia austriaca).

Отличия таксономического состава скарабеид на разных участках (кроме газонов, где представители надсемейства единичны), обусловили сравнительно высокие различия их фаунистического сходства (табл. 2). Так, коэффициенты Жаккара / Чекановского - Серенсена колебались от 0,17/0,31 до 0,50/0,67 (при среднем значении всего $0,20 / 0,47$ ). Наименьшее сходство отмечено для парка Зеленый гай, $(0,21-0,32 / 0,35-0,42)$ по сравнению с другими участками, а также парком Победы и Харьковским лесопарком $(0,17 / 0,31)$. Максимальные показатели сходства наблюдаются при сравнении скарабеидофаун территорий Карповского сада, Лесопарка и парка Победы $(0,38-0,50 / 0,61-0,67)$. Наименьшие фаунистические показатели отмечены в парке Зеленый гай $(0,21-0,32 /$ 0,35-0,47). При сравнении видового состава отдельных парков с агроценозами, уровень фаунистического сходства оказался еще ниже $(0,18-0,31 / 0,31-0,56)$, а общей таксономической структуры парковых ценозов и полевых культур - только 0,33/0,50. 
Таблица 1

Качественно-количественная и экологическая характеристики Scarabaeoidea урбоценозов Харькова

\begin{tabular}{|c|c|c|c|c|c|c|c|c|c|}
\hline \multirow[b]{2}{*}{ Таксоны (семейства, подсемейства, рода, виды) } & \multicolumn{6}{|c|}{ Встречаемость в парках и других стациях } & \multicolumn{3}{|c|}{ Экологические группы по: } \\
\hline & лесопарк & $\begin{array}{l}\text { Зеленый } \\
\text { гай }\end{array}$ & $\begin{array}{c}\text { Карпо- } \\
\text { вский сад }\end{array}$ & Победы & газоны & $\begin{array}{c}\text { агро- } \\
\text { ценозы }\end{array}$ & биотопу & $\begin{array}{l}\text { влаж- } \\
\text { ности }\end{array}$ & трофике \\
\hline & & & Lucanidae & & & & & & \\
\hline Dorcus parallelopipedus (Linnaeus, 1758) & ++ & + & + & + & - & - & ЛС & M3 & СДФ \\
\hline Platyderes caraboides (Linnaeus, 1758) & ++ & + & $\begin{array}{c}(+) \\
\text { Troxidae }\end{array}$ & - & - & - & ЛС & M3 & СДФ \\
\hline Trox hispidus Pontoppidan, 1763 & - & - & $\begin{array}{l}\stackrel{+}{+} \\
\text { Geotrupidae: } \\
\text { Geotrupinae }\end{array}$ & + & - & $(+)$ & $Л \Gamma$ & МЗК & НСФ \\
\hline Anoplotrupes stercorosus (Scriba, 1791) & ++ & - & $\begin{array}{c}+ \\
\text { Lethrinae }\end{array}$ & - & - & - & ЛС & M3 & СФ \\
\hline Lethrus apterus (Laxmann, 1770) & - & - & \begin{tabular}{l}
\multicolumn{1}{c}{} \\
Scarabaeidae: \\
Aphodiinae
\end{tabular} & - & - & $(+)$ & $Л \Gamma$ & M3 & $\Phi \Phi$ \\
\hline Aphodius (Eurodalus) coenosus, (Panzer, 1798) & - & - & - & + & - & - & ПТ & M3 & СКФ \\
\hline A. (Bodilus) lugens Creutzer, 1799 & - & - & - & $(+)$ & - & - & $Л \Gamma$ & M3 & СКФ \\
\hline A. (B.) punctipennis Erichson, 1848 & $(+)$ & - & - & - & - & - & ЛГ-ЛС & МЗК & СКФ \\
\hline A. (Chilothorax) distinctus (O. Müller, 1776) & + & $(+)$ & + & - & - & ++ & ПТ & M3 & СКФ \\
\hline A. (Ch.) melanostictus W. Schmidt, 1840 & - & + & - & + & & + & ЛГ-СТ & M3 & СКФ \\
\hline A. (Colobopterus) erraticus (Linnaeus, 1758) & + & - & $(+)$ & - & - & + & ПТ & M3 & СКФ \\
\hline A. (Eudolus) quadriguttatus (Herbst, 1783) & $(+)$ & - & - & - & - & $(+)$ & ПТ & M3 & СКФ \\
\hline A. (Melinopterus) prodromus Brahm, 1790 & - & - & + & - & - & - & ЛГ-СТ & M3 & СКФ \\
\hline A. (s. str.) fimetarius (Linnaeus, 1758) & $(+)$ & - & - & - & - & - & ПТ & M3 & СКФ \\
\hline A. (Volinus) sticticus (Panzer, 1798) & + & - & + & + & - & + & ЛГ & M3 & СКФ \\
\hline Pleurophorus caesus (Creutzer, 1796) & - & - & $\begin{array}{c}(+) \\
\text { Scarabaeinae }\end{array}$ & - & $(+)$ & ++ & ПТ & M3 & СФ \\
\hline $\begin{array}{l}\text { Onthophagus (Paleonthophagus) coenobita } \\
\text { (Herbst, 1783) }\end{array}$ & + & ++ & (1) & ++ & - & - & ПТ & M3 & СКФ \\
\hline O. (P.) nuchicornis (Linnaeus, 1758) & $(+)$ & - & $(+)$ & - & - & $(+)$ & ПТ & M3 & СКФ \\
\hline O. (P.) ovatus (Linnaeus, 1758) & $(+)$ & - & $(+)$ & - & - & - & ПТ & M3 & СКФ \\
\hline O. (P.) verticicornis (Laicharting, 1781) & - & - & - & $(+)$ & - & - & $\pi \Gamma$ & M3 & СКФ \\
\hline O. (P.) vitulus (Fabricius, 1776) & - & - & $\begin{array}{l}(+) \\
\text { Melolonthinae }\end{array}$ & $(+)$ & - & - & ЛГ-СТ & МЗК & СКФ \\
\hline Amphimellon solstitiale (Linnaeus, 1758) & - & $(+)$ & + & + & - & ++ & ПТ & M3 & ФФ \\
\hline Anoxia (s. str.) pilosa (Fabricius, 1792) & - & - & + & $(+)$ & - & + & ЛС-КС & M3 & $\Phi \Phi$ \\
\hline Melolontha melolontha (Linnaeus, 1758) & - & + & $\begin{array}{c}+ \\
\text { Sericinae }\end{array}$ & + & - & ++ & ПТ & M3 & $\Phi \Phi$ \\
\hline Maladera (s. str.) holosericea (Scopoli, 1772) & - & + & - & + & - & - & ПТ & M3 & ФФ \\
\hline Omaloplia (s. str.) ruricola (Fabricius, 1775) & - & $(+)$ & & - & - & - & ЛГ & M3 & $\Phi Ф$ \\
\hline Serica brunnea (Linnaeus, 1758) & $(+)$ & - & $\begin{array}{c}(+) \\
\text { Rutelinae }\end{array}$ & + & - & - & ЛС-КС & M3 & $\Phi \Phi$ \\
\hline Anisoplia (Autanisoplia) austriaca (Herbst, 1783) & - & - & - & - & - & +++ & ЛГ & M3 & $\Phi \Phi$ \\
\hline Anomala (s. str.) dubia (Scopoli, 1763) & - & - & + & + & - & $(+)$ & ЛГ & M3 & ФФ \\
\hline Chaetopteriphilus segetum (Herbst, 1783) & - & - & $\begin{array}{c}- \\
\text { Dynastinae }\end{array}$ & - & - & ++ & ЛГ & M3 & $\Phi \Phi$ \\
\hline Oryctes (s. str.) nasicornis (Linnaeus, 1758) & - & - & $(+)$ & - & - & - & ЛС & M3 & СФФ \\
\hline Pentodon idiota (Herbst, 1789) & - & - & $\begin{array}{c}- \\
\text { Cetoniinae }\end{array}$ & - & - & ++ & ЛГ-СТ & M3 & $\Phi \Phi$ \\
\hline Oxythyrea funesta (Poda, 1761) & - & - & $(+)$ & + & - & - & ПТ & M3 & $\Phi \Phi$ \\
\hline Propaetia (Potosia) metallica (Herbst, 1782) & - & - & $(+)$ & + & - & - & ПТ & M3 & СФФ \\
\hline Tropinota hirta (Poda, 1761) & - & - & - & $(+)$ & - & - & ПТ & M3 & $\Phi \Phi$ \\
\hline Valgus hemipterus (Linnaeus, 1758) & - & + & + & $(+)$ & - & - & ЛС & M3 & $\Phi \Phi$ \\
\hline Всего видов / из них обычных & $13 / 3$ & $10 / 1$ & $20 /-$ & $19 / 1$ & $1 /-$ & $16 / 8$ & & $36 / 12$ & \\
\hline
\end{tabular}

Примечания: встречаемость: +++ - массовый, ++ - обычный, + - редкий, (+) - единичный вид; биотопическая приуроченность: ПТ - политопный, ЛС - лесной, ЛГ - луговой, СТ - степной, КС - кустарниковый; гигропреферендум: МЗ - мезофил, МЗК - мезоксерофил; трофическая специализация: ФФ - фитофаг, СФ - сапрофаг (широкий), СФФ - сапрофитофаг, СКФ - сапрокопрофаг, НСФ - некросапрофаг, СДФ - сапродендрофаг.

\section{Таблица 2}

Видовое сходство Scarabaeoidea парковых насаждений Харькова и прилегающих агроценозов (коэффициенты Жаккара / Чекановского - Серенсена)

\begin{tabular}{|c|c|c|c|c|c|c|}
\hline Парки & Лесопарк & Карповский сад & Победы & Зеленый гай & Газоны & Агроценозы \\
\hline Лесопарк & - & 0,61 & 0,31 & 0,35 & 0,00 & 0,41 \\
\hline Карповский сад & 0,38 & - & 0,67 & 0,47 & 0,10 & 0,56 \\
\hline Победы & 0,17 & 0,50 & - & 0,41 & 0,00 & 0,40 \\
\hline Зеленый гай & 0,21 & 0,30 & 0,32 & - & 0,00 & 0,31 \\
\hline Газоны & 0,00 & 0,08 & 0,00 & 0,00 & - & 0,12 \\
\hline Агроценозы & 0,21 & 0,38 & 0,39 & 0,18 & 0,00 & - \\
\hline
\end{tabular}

Согласно биотопической приуроченности (табл. 1), большинство видов герпетобионтных жуков относятся к трем основным группам: политопная (15), луговая (6) и лесная (5). Отдельные виды относятся к переходным подгруппам: лесокустарниковой
(2), луго-степной (3) и луго-лесной (1 вид). Политопные (эврибионтные) виды, зарегистрированные в парках, встречаются и в большинстве других трансформированных биотопов. Представители лесной группы чаще встречались в крупных парковых на- 
саждениях (Лесопарк), но спорадично и в других, не уступая здесь по численности политопным видам. Луговые элементы тяготеют к паркам с изреженным древостоем и отдельными открытыми участками (Карповский сад, Победы), но являются доминантами (наравне с политопными) в агроценозах. По отношению к влажности преобладающее число видов скарабеид являются широкими мезофилами и существенных различий среди этих экологических групп не наблюдается. Единичные мезоксерофилы (3 вида) зарегистрированы как случайные, и только Trox hispidus иногда отмечен как редкий вид.

Практически все представители семейств Lucanidae, Troxidae, большинство Geotrupidae и Scarabaeidae (подсемейства Aphodiinae и Scarabaeinae), являющиеся сапрофагами разной специализации (дендрофагами, копрофагами, некрофагами), чаще встречались в парковых ценозах, тогда как фитофаги - в агроэкосистемах.

\section{Обсуждение}

В результате наших исследований выявлено достаточно высокое видовое разнообразие скарабеоидных жуков парковых насаждений Харькова (32 вида из 22 родов). По отдельным литературным данным (Dekhtyarova, 2002), ранее в харьковских парках зарегистрировано 15 видов из 11 родов и двух семейств. К сожалению, в этой работе приведены только обобщенные количественные сведения на уровне отдельных семейств Scarabaeoidea без указаний таксономического состава этих жуков (даже на уровне основных родов и видов). В одной из недавних публикаций (Putchkov et al., 2016) имеются отрывочные данные всего о трех видах пластинчатоусых жуков, зарегистрированных в парках Харькова. Фрагментарные сведения по отдельным видам пластинчатоусых жуков (например, Amphimellon solstitiale Linnaeus, 1758, Oryctes nasicornis Linnaeus, 1758) приведены и для некоторых городов Средней Европы (Klausnitzer, 1990). В урбоценозах отдельных городов Беларуси отмечено четыре вида из двух семейств Scarabaeoidea (Molodova, 1991; Galinovskiy, 2006). В сравнительном аспекте, по числу видов Scarabaeoidea, харьковские парки превышали таковые показатели прилегающих агроценозов, хотя и уступали им по общей численности (за счет некоторых вредителей сельского хозяйства из подсемейства Melolonthinae).

Фаунистическое сходство скарабеоидных жуков большинства парков оказалось невысоким, особенно при сравнении с территориями, подверженными значительной урбанизации (например парка Зеленый гай, как места активного отдыха, наличия стадиона и других спортивных сооружений). Среднее значение вариации коэффициента Жаккара, составляющее чуть более $30 \%$, может свидетельствовать об определенной специфичности в составе пластинчатоусых жуков обследованных парковых участков, что в некоторой мере подтверждается биотопической приуроченностью болышинства видов Scarabaeoidea, причем не только к определенным урбанизированным биотопам, но и другим трансформированным ценозам. Но характер таких различий можно объяснить также низкой численностью большинства видов, встречаемость которых на всех участках носит случайный характер. При этом на уровне обычных видов фаунистическое сходство отсутствует. Вместе с тем, по гигропреферендуму различий в разных трансформированных ценозах не выявлено, что объясняется доминированием в каждой из стаций мезофильных видов.

Более существенные фаунистические различия, в разных по степени трансформации ценозах, наблюдаются в соотношении трофических групп Scarabaeoidea и ярусности обитания отдельных видов. Фитофаги (подсемейства Melolonthinae, Rutelini) преобладали в агроценозах (дендробионты подсемейства Melolonthinae - в садах, a Rutelini - на полевых культурах), тогда как в парковых стациях доминировали типичные (Troxidae, подсемейства Арhodiinae и Scarabaeinae) и, относительно, герпетобионтные виды (Lucanidae, некоторые Geotrupidae, Dynastinae, Sericinae) (табл. 1).

Таким образом, определенные различия ряда видов надсемейства по большинству экологических показателей в значительной мере определяют и уровень фаунистического сходства.

\section{Выводы}

В парковых насаждениях Харькова выявлено 32 вида Scarabaeoidea из четырех семейств. По видовому составу и численности доминировали Scarabaeidae (26 видов из 16 родов). Остальные семейства представлены одним - двумя видами. Спорадично обычными оказались только шесть видов, причем в отдельных урбоценозах их число не превышало одного - трех. Видовой состав и численность скарабеид оказались выше в крупных парках (Харьковский лесопарк, Карповский сад и Победы), где отмечено от 13 до 20 видов. На газонах как центра, так и микрорайонов города пластинчатоусые жуки встречались единично. В прилегающих к Харькову агроценозах отмечено 16 видов, из которых почти половина - зарегистрированы как относительно обычные. Показатели фаунистических оказались чуть выше $(0,38$ 0,50 по Жаккару и 0,61-0,67 по Чекановскому - Серенсену) для территорий с меньшей рекреационной нагрузкой, чем для парковых участков (Зеленый гай) со значительным антропогенным прессом $(0,21-0,32 / 0,35-0,47)$. Уровень фаунистического сходства отдельных парков и агроценозов оказался еще ниже $(0,18-0,31 /$ $0,31-0,56$, в среднем - 0,33/0,50). Такие различия обусловлены как низкой численностью большинства видов, так и некоторыми экологическими характеристиками видов. Основные различия наблюдались в соотношении трофических групп и ярусности обитания основных видов. По трофической специализации в парках доминировали герпетобионтные сапрофаги разной специализации (в основном копрофаги и дендрофаги), тогда как в агроценозах преобладали фитофаги-дендрохортобионты. Меньше различий отмечено по биотопической приуроченности видов. В каждом из ценозов доминировали политопные, меньше - лесные и луговые виды. Почти все они представлены широкими мезофилами. Приведенный эколого-фаунистический обзор Scarabaeoidea урбанизированных участков Харькова является предварительным. В дальнейшем исследования будут продолжены и расширены, что позволит дать комплексную оценку всей напочвенной колеоптерофауны, проанализировать особенности ее формирования и выявить характер сезонных изменений численности доминантных видов в трансформированных ценозах мегаполиса.

Авторы статьи выражают искреннюю благодарность сотруднику Института зоологии имени И. И. Шмальгаузена НАН Украины (г. Киев) Б. Н. Васько за определение некоторых скарабеоидных жуков, а также сотрудникам Харьковского национального педагогического университета имени Г. С. Сковороды М. Ю. Скавышу и Н. Ю. Николенко за помощь в сборе материала.

\section{References}

Browne, J., \& Scholtz, C. H. (1999). A phylogeny of the families of Scarabaeoidea (Coleoptera). Systematic Entomology, 24, 51-84.

Buse, J., Martin Šlachta, M., Sladecek, F. X. J., Markus Pung, M., Wagner, T., \& Entling, M. H. (2015). Relative importance of pasture size and grazing continuity for the long-term conservation of European dung beetles. Biological Conservation, 187, 112-119.

Buyvolova, A. Y., Rakhleeva, A. A., Buyvolov, Y. A. (2016). The structure of mesofauna complexes in soils of the forest-park zone of Moscow and the Prioksko-Terrasnyi Biospheric Reserve. Eurasian Soil Science, 49, 1392.

Catalogue of Palearctic Coleoptera (2006). Vol. 3. Scarabaeoidea - Scirtoidea Dascilloidea - Buprestoidea - Byrrhoidea. Apollo Books, Stenstrup.

Dekhtyareva, E. A. (2002). Zoogeograficheskiy biotopicheskiy i ekologicheskiy analiz pedofauny nasekomykh lesoparkov goroda Kharkova [Zoogeographical, biotopical and ecological analysis of the insects pedofauna of the forest parks in Kharkov]. Izvestiya Kharkovskogo Entomologicheskogo Obshchestva, 10, 123-125 (in Russian).

Dortel, E., Thuiller, W., Lobo, J. M., Bohbot, H., Lumaret, \& Jay-Robert, J. P. P. (2013). Potential effects of climate change on the distribution of Scarabaeidae dung beetles in Western Europe. Journal of Insect Conservation, 17(5), 1059-1070.

Galante, E. M., \& Cartagena, C. (1999). Comparison of mediterranean dung beetles (Coleoptera: Scarabaeoidea) in cattle and rabbit dung. Environmental Entomology, 28(3), 420-424. 
Galinovskiy, N. G. (2006). Nekotorye biologo-ekologicheskiye osobennosti zhestkokrylykh-herpetobiontov (Insecta, Coleoptera) urbotsenozov goroda Minska [Some biological and ecological features of the herpetobiont beetles (Insecta, Coleoptera) of the urbocenoses of Minsk city]. Sakharovskiye chteniya 2006 goda: Ekologicheskiye problemy XXI veka. Materialy 6 Mezhdunarodnoi nauchnoi konferentsii. MGEU im. A. D.Sakharova, Minsk. pp. 295-297 (in Russian).

Klauznitser, B. (1990). Ekologiya gorodskoy fauny [Ecology of urban fauna]. Mir, Moscow (in Russian).

Markina, T. Y., \& Zlotin, A. Z. (2014). Zhiznesposobnost populyatsiy nasekomykh kak pokazatel urovnya zagryazneniya okruzhayushchey sredy pri bioindikatsionnykh issledovaniyakh ekosistem [Viability of insect populations as an indicator of the level of environmental pollution in bioindicative studies of ecosystems]. Izvestiya Kharkovskogo Entomologicheskogo Obshchestva, 22, 37-43 (in Russian).

Martynov, V. V. (1997). Ekologo-faunisticheskiy obzor plastinchatousykh zhukov (Coleoptera. Scarabaeidae) Yugo-Vostochnoy Ukrainy [Ecological and faunal survey of Lamellicom beetles (Coleoptera, Scarabaeidae) of Southeastem Ukraine]. Izvestiya Kharkovskogo Entomologicheskogo Obshchestva, 5(1), 22-73 (in Russian).

Molodova, L. P. (1991). Kolichestvennaya i kachestvennaya kharakteristika zhukov herpetobiontov v rayone krupnogo promyshlennogo obyedineniya $\mathrm{v}$ Gomele [Quantitative and qualitative characteristics of herpetobiont beetles in the district of large industrial association in Gomel city]. In: Fauna ekologiya zhestkokrylykh Belorussii. Nauka i Tekhnika, Minsk. pp. 185-192 (in Russian).

Price, D. L. (2004). Species diversity and seasonal abundance of Scarabaeoid dung beetles (Coleoptera: Scarabaeidae, Geotrupidae and Trogidae) attracted to cow dung in Central New Jersey. Journal of the New York Entomological Society, 112(4), 334-347.
Putchkov, A. V. (1990). Zhestkokrylye (Coleoptera) pshenichnogo polya yugozapada stepnoy zony Evropeyskoy chasti SSSR [The beetles (Coleoptera) of wheat fields of Southwestern part of Steppe zone of the European part of the USSR]. Entomologicheskoye Obozreniye, 69(3), 538-549 (in Russian).

Putchkov, A. V. (2009). Zhuky-saprofagi (Insecta: Coleoptera) agrotsenoziv Ukrainy [The saprophagous beetles (Insecta: Coleoptera) of agrocenoses of Ukraine]. Biology and Valeology, 11, 8-88 (in Ukrainian).

Putchkov, A. V., Markina, T. Y., \& Skavysh, M. (2016). Predvaritelnyj obzor herpetobiontnykh zhukov (Coleoptera) parkovykh nasazhdeniy goroda Kharkova (Ukraina) [Preliminary review of herpetobiont beetles (Coleoptera) of Kharkov parkland (Ukraine)]. Ukranian Entomological Journal, 11, 69-76 (in Russian).

Putchkov, O. V., \& Gavrilyuk, N. M. (2010). Osoblivosti formuvannya struktury tverdokrylikh komakh (Insecta, Coleoptera) na perelogakh ta v agrotsenozi ozymoj pshenitsi [Peculiarities of the beetles structure (Insecta, Coleoptera) on the field deposits and in winter wheat agrocenosis]. Karantin ta Zakhist Roslin, 169(7), 2-7 (in Ukrainian).

Smith, A. B. T. (2006). A review of the family-group names for the superfamily Scarabaeoidea (Coleoptera) with corrections to nomenclature and a current classification. The Coleopterists Bulletin, 60, 144-204.

Sumarokov, A M. (2009). Vosstanovleniye bioticheskogo potentsiala biogeotsenozov pri umenshenii pestitsidnykh nagruzok [Rehabilitation of the biotic potential of biocenoses with a decrease of the pesticide loads]. Veber, Donetsk (in Russian).

Vas'ko, B. N. (2010). Fauna i ekologiya plastinchatousykh zhukov Pravoberezhnoj Ukrainy [Fauna and ecology of Lamellicom beetles of Right-bank of Ukraine]. Izvestiya Kharkovskogo Entomologicheskogo Obshchestva, 17(1), 4-86 (in Russian).

Verdú, J. R., Galante, E., Lumaret, J.-P, \& Cabrero-Sañudo, F. J. (2004). Phylogenetic analysis of Geotrupidae (Coleoptera, Scarabaeoidea) based on larvae Systematic Entomology, 29(4), 509-523. 